Scientia Agricola

http://dx.doi.org/10.1590/0103-9016-2013-0360

\title{
Effect of partial soil wetting on transpiration, vegetative growth and root system of young orange trees
}

\author{
Lucas Melo Vellame $^{1 *}$, Eusímio Felisbino Fraga Júnior², Rubens Duarte Coelho²
}

${ }^{1}$ Federal University of Bahia Reconcavo - Center for Agricultural Sciences, Biological and Environmental - Dept. of Water Engineering and Soil, R. Rui Barbosa, 710- 44380000 - Cruz das Almas, BA - Brazil.

2University of São Paulo/ESALQ - Dept. of Biosystems

Engineering, C.P. 09 - 13418-900 - Piracicaba, SP - Brazil.

*Corresponding author <lucasvellame@gmail.com>

Edited by: Gerrit Hoogenboom

Received October 31, 2013

Accepted May 01, 2015

\begin{abstract}
The wetted area fraction is a factor critical to the success of drip irrigation. This study aimed to evaluate the effect of partial soil wetting on transpiration, vegetative growth and root system of young orange trees. The experiment was carried out in a greenhouse where plants were grown in $0.5 \mathrm{~m}^{3}$ boxes internally divided into compartments. The wetting of $12 \%$ of soil area was tested on two types of soil cultivated with 'Valencia' orange trees grafted onto Rangpur lime and 'Swingle' citrumelo rootstocks. Transpiration was determined in 40 plants. Water extraction and root density were evaluated in the compartments. Transpiration is reduced by restriction in wetted soil area, and such reduction is influenced by the number of days after the beginning of partial irrigation, atmospheric evaporative demand and plant phenological stage. Mean transpiration of plants with partial irrigation was equivalent to $84 \%$ of the mean transpiration of plants with $100 \%$ of wetted soil area in the period studied. However, after 156 days of imposing partial irrigation there was no difference in transpiration between treatments. Plant acclimation was caused by an increase in root concentration in the irrigated area. After a period of acclimation, if the entire root system is wetted, soil water extraction becomes proportional to the percentage of wetted area after a short period of time. Despite the reduction in transpiration, there was no difference between treatments with $12 \%$ and $100 \%$ of wetted soil area in terms of vegetative growth.

Keywords: drip irrigation, sap flow, wetted bulb, root length density
\end{abstract}

\section{Introduction}

The increasing conflicts between sectors that use water resources have raised the importance of localized irrigation. One of the factors critical to the adoption and economic conduction of drip irrigation is the definition of the wetted area (WA). Working with irrigated Pomelo (Citrus maxima) in Florida, Zekri and Parsons (1989) observed that roots are confined to a small soil volume. However, in some places in Florida, where the climate is humid and rainy, roots are not confined to this wetted volume created by the emitters. In the southeast of Brazil, where national citrus production is concentrated, the dry season of the year coincides with the coldest months. These circumstances might be conditioning root system development outside the wet bulb. In Brazil, the largest citrus producing country, single-line irrigation has been adopted, in approximately $12 \%$ of the WA.

Under field conditions, some researchers evaluated fruit production and quality with different percentages of WA (Bielorai, 1982; Koo, 1985; Castel, 1994). In some of these studies, it was not possible to determine with certainty if the effects on fruit production and quality resulted from a reduction in plant transpiration caused by the decrease in the WA. Water relations, production and fruit quality have been evaluated in the last years under strategies like irrigation deficit and partial root zone drying (PRD) (Domingo et al., 1996; Treeby et al., 2007; Hutton and Loveys, 2011). However, under the PRD regime, it is not possible to separate the effects of irrigation alternation and WA restriction, as occurs in continuous drip irrigation.
The main difficulties in field experiments as in the case of WA investigations, especially using perennial plants, are the study of the root system and the determination of transpiration of the great number of plants involved in the experiment. Currently, most of the studies on plant transpiration measurements, especially in woody fruit trees, are based on methods of heat supply in the trunk (Lu et al., 2002; Yonemoto et al., 2004; Coelho Filho et al., 2005; Ferreira et al., 2012; Vellame et al., 2012).

This study aimed to evaluate the effect of partial soil wetting on water relations and vegetative growth of young 'Valencia' orange trees (Citrus sinensis) grafted on to 'Swingle' citrumelo (Citrus paradise $\times$ Poncirus trifoliate) and Rangpur lime (Citrus limonia) rootstocks, in sandy and clay soils.

\section{Materials and Methods}

The experiment was carried out from Oct 2008 to Jan 2011, in a greenhouse, located in Piracicaba, in the state of São Paulo, Brazil $\left(22^{\circ} 42^{\prime} 32^{\prime \prime}\right.$ S; 47 $37^{\prime} 45^{\prime \prime}$ W; $548 \mathrm{~m})$. The effect of partial soil wetting was evaluated using $12 \%$ of wetted area in two types of soil cultivated with young 'Valencia' orange trees grafted onto Ranpur lime and 'Swingle' citrumelo rootstocks. The seedlings were transplanted in Oct 2008 (Figure 1A, 1B). The treatment with reduction of wetted soil area began at 524 days after planting the seedlings. 805 days after planting, all plants came back to $100 \%$ of the soil volume irrigated. 
In the greenhouse there were 54 boxes of $0.5 \mathrm{~m}^{3}$ each, distributed in four rows, two of which were filled with sandy loamy soil and two filled with clayey soil (Table 1). The central rows were used to test the $12 \%$ of wetted area fraction (12\% WA). Plants with $100 \%$ of wetted area were set externally, around the others, to avoid the wetting through the rain in the restricted wetted area treatments, since there were no lateral curtains in the greenhouse.

The seedlings were transplanted with nude roots, allowing for uniform development in all compartments. Only after this development was the treatment with reduction of wetted area applied at the initial stage of the experiment. Thus, irrigation and fertigation were conducted to obtain the highest possible uniformity in the entire box. For this, self-compensating drippers with different flow rates connected to flow dividers were used in the compartmented boxes. Flow rates of $4 \mathrm{~L} \mathrm{~h}^{-1}, 2 \mathrm{~L}$ $\mathrm{h}^{-1}$ and $1 \mathrm{~L} \mathrm{~h}^{-1}$ were applied, respectively, in the compartments corresponding to $50 \%, 25 \%$ and $12 \%$ of the box (Figure $1 \mathrm{C}$ ). Drippers with $8 \mathrm{~L} \mathrm{~h}^{-1}$, with flow dividers, were used in the undivided boxes.

Before the application of WA treatments, sap flow variability was analyzed for 30 days in order to determine the minimal number of plants that would have reduction in soil wetted area. The experimental structure allowed for testing six wetted area percentages. However, because of the variability found, irrigation was conducted in order to moisten only the compartment corresponding to $12 \%$ of the box volume, in all compartmented boxes. This choice was made in order to guarantee statistical significance in the results for the highest number of replicates.

The treatment with reduction of wetted soil area began in Mar 2010. Irrigation was suspended in the total area of the box, and then only the compartment with $12 \%$ of the soil volume was irrigated. At this stage, the same dripper from the non-irrigated boxes $\left(8 \mathrm{~L} \mathrm{~h}^{-1}\right)$ was used. Irrigation was applied at the rate of once or twice per day by keeping water content close to field capacity (Figure 1D).

Reference evapotranspiration (ETo, $\mathrm{mm} \mathrm{d}^{-1}$ ) was calculated by the Penman-Monteith method, proposed by the FAO with a wind speed of $0.5 \mathrm{~m} \mathrm{~s}^{-1}$. In general, the

Table 1 - Physical analysis of soils used in the experiment.

\begin{tabular}{cccccc}
\hline \multirow{2}{*}{ Soil layer } & $\begin{array}{c}\text { Available water } \\
\text { capacity }\end{array}$ & $\begin{array}{c}\text { Bulk } \\
\text { density }\end{array}$ & \multicolumn{3}{c}{ Particle distribution (\%) } \\
\cline { 3 - 6 } $\mathrm{m}$ & $\mathrm{mm}$ & $\mathrm{g} \mathrm{cm}^{-3}$ & & Sand & Clay \\
\hline $0.00-0.15$ & 18.1 & 1.53 & 75 & 8 & 17 \\
$0.15-0.30$ & 19.4 & 1.50 & 74 & 8 & 18 \\
$0.30-0.45$ & 16.5 & 1.69 & 74 & 9 & 17 \\
\hline $0.00-0.15$ & 22.3 & 1.28 & 31 & 15 & 54 \\
$0.15-0.30$ & 24.0 & 1.27 & 31 & 16 & 53 \\
$0.30-0.45$ & 24.0 & 1.31 & 30 & 17 & 53
\end{tabular}

${ }^{*}$ Field capacity corresponding at a potential of $4.85 \mathrm{kPa}$ and permanent wilting point at $1500 \mathrm{kPa}$.
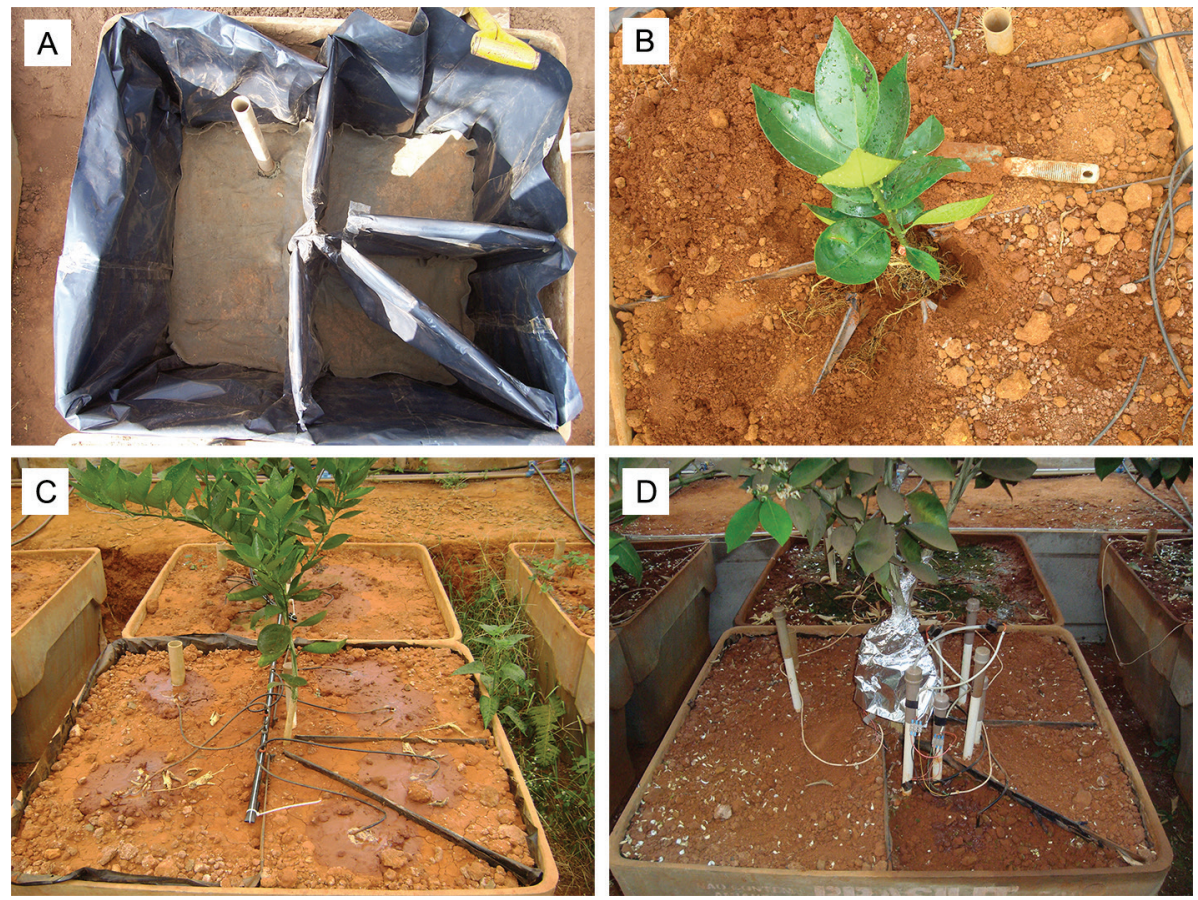

Figure 1 - Boxes internal divisions (A), seedling planting (B) and irrigation in the initial stage (C) and during the application of the $12 \%$ wetted area treatment (D). 
wind speed at $2 \mathrm{~m}$ must be fixed at a minimum value of $0.5 \mathrm{~m} \mathrm{~s}^{-1}$, when it is used in the ETo equation (Allen et al., 1998). Global solar radiation was measured by pyranometer and relative air humidity and temperature by Vaisala sensors, installed at $2 \mathrm{~m}$ in the center of the greenhouse.

\section{Soil water extraction and root length density}

Soil water potential was measured by tensiometers installed at depths of 0.15 and $0.45 \mathrm{~m}$ in all the compartments of the boxes. Pressure transducers were installed in 48 tensiometers (six boxes) in order to maintain continuous monitoring. The other readings were performed through puncture tensiometers (manual readings). Volumetric water content was calculated using the Genuchten (1980) equation and water consumption in each compartment through the variation in water storage.

The contribution of each box compartment to evapotranspiration was determined through the difference in soil water storage in two periods: Jan 2010, before the reduced wetted area treatment began, and Jan 2011, at the end of the experiment, when all plants came back to $100 \%$ of the soil volume irrigated. At the end of the experiment, the root system of all plants for each compartment was sampled, using a $1.35-\mathrm{m}$ in long steel cylinder with a $0.10-m$ diameter. Roots were separated from the soil by immersion in water, and then sieved through a grid of $2.0 \mathrm{~mm}$. Samples were digitalized and the sum of root length was obtained using the Safira 2010 software.

\section{Transpiration}

Plant transpiration was estimated in 40 plants through sap flow measurements, from 18 Jan 2010 to 19 Sep 2010. The heat dissipation probe (HDP) method was chosen because of the low cost of sensors and the smaller number of differential channels needed for the measurements, thus allowing measurements in a higher number of plants in the experiment. Each sensor is comprised of a probe heated at a constant power and a non-heated probe (reference probe), both having internally a thermocouple. The $10-\mathrm{mm}$ probes were built using copper-constantan thermocouples with a $0.5-\mathrm{mm}$ diameter, inserted in 1-mm-diameter needles and filled with resin for fixation.

The plant stem diameters were measured at the insertion point of the superior probe. The entire trunk section was considered as an effective xylem section conducting raw sap $\left(\mathrm{AS}, \mathrm{m}^{2}\right)$. Steppea et al. (2010) concluded in laboratory that a specific calibration for the species is necessary when using heat pulse, heat dissipation and heat field deformation techniques, in order to guarantee accurate estimations of sap flow density. The sap flow $\left(F S, \mathrm{~m}^{3} \mathrm{~s}^{-1}\right)$ was calculated by the Eq. 1 calibrated through the lysimetric measurements according to Coelho et al. (2012).

$\mathrm{FS}=\mathrm{AS} 0.000594\left(\frac{\Delta \mathrm{Tx}-\Delta \mathrm{T}}{\Delta \mathrm{T}}\right)^{1.231}$ where: $\Delta \mathrm{T}$ is the temperature difference between the probes $\left({ }^{\circ} \mathrm{C}\right)$; and $\Delta \mathrm{Tx}$ the temperature difference between probes at zero flow, when there is only heat loss by conduction $\left({ }^{\circ} \mathrm{C}\right)$.

To correct the effects of natural thermal gradients in the stem, the thermal differences were measured with the non-heated sensor during the periods of time different from those during which the sap flow was measured. Estimation models of the natural thermal differences (NTD) were created for each probe individually as a function of a reference probe. The collected data of thermal differences between probes were corrected based on these models. Signals from the thermocouples were measured using a data acquisition and storage system with readings every $30 \mathrm{~s}$ and mean values stored every $15 \mathrm{~min}$.

Transpiration and ETo were related through segmented regression analysis, minimizing the root mean square error (RMSE) between observed and calculated transpiration. Daily transpiration $(\mathrm{Tr})$ data were divided into groups according to the ETo of the day, in terms of values of low and high atmospheric evaporative demand. The limit between these classes was determined by the ETo value at which the ratio Tr/ETo changes, through the water loss control by the plant (Vellame et al., 2012). After the drying of the non-irrigated compartments, the percentage of transpiration (PTr) was calculated by the relationship between the transpiration of each plant and the average transpiration of plants with $100 \%$ wetted area (100\% WA).

The data were divided into periods according to phenological stage. The distinction between stages was made by visual observation of leaf formation and fall, identification of already differentiated flower buds and fruit development. The vegetative development stage lasted 595 days after planting the seedlings. The rest period preceded the observation of flower buds in 51 days. The flowering stage lasted 34 days when fruiting started.

\section{Vegetative growth}

Leaf area and stem diameter were measured at the beginning and at the end of the evaluation (Jan 2010 and Oct 2010). At first evaluation, leaf area $\left(A F, m^{2}\right)$ was determined in a plant that visually represented the experiment. Total number of leaves per plant was counted and the highest length $(\mathrm{C}, \mathrm{m})$ and width $(\mathrm{L}, \mathrm{m})$ of the total number of leaves from one of the plants were measured. Leaf area of each leaf was calculated by Eq. 2 (Coelho Filho et al., 2005).

$\mathrm{AF}=0.72 \mathrm{C} \mathrm{L}$

The total number of leaves in the other plants was counted, and the lengths and widths of $14 \%$ of the leaves ( 1 leaf in every 7 ) were measured. This percentage was set based on the frequency distribution of the data obtained from the plant considered as representative, for an error in estimation less than $5 \%$. 


\section{Statistical analysis}

Five plants were used as replicates for each of the eight treatments derived from the combination of two wetted areas, two soil types and two rootstocks. The statistical analysis of the transpiration and root length density was performed using SAS statistical software. Transpiration data were subjected to analysis of variance (ANOVA) with the following as sources of variation: crop development stage, planting row, soil type, rootstock, soil wetted area and class of atmospheric evaporative demand. The F-test was used to show the probability of differences between means. The data of root length, density stem diameter and leaf area were submitted to ANOVA with the following as sources of variation: the row, soil type, rootstock and soil wetted area. Tukey's test with a probability of $5 \%$ was used to differentiate the means of these variables.

\section{Results and discussion}

\section{Transpiration}

Reduction in the soil wetted area caused a decrease of $16 \%$ in the average transpiration of plants during the study, a very substantial difference $\mid p<$ 0.001). There was no interaction with the crop development stage and the class of atmospheric evaporative demand $(p>0.055)$. There were no interactions between soil type and rootstocks and the wetted area fraction $(p$ $>0.05)$.

The lack of significant difference in transpiration with the two soil types may be explained by the high-frequency irrigation management. For the two soil types, water contents were kept close to field capacity. The maximal variation of water storage was $5 \%$ in the treatment with $100 \% \mathrm{WA}$ and $45 \%$ in the treatment with $12 \%$.

Based on data from this same experiment, Vellame et al. (2012) observed significant effect of rootstock on the transpiration of plants with $100 \% \mathrm{WA}$, due to the high conductivity of Rangpur lime roots. However, rootstocks did not respond differently to the reduction in wetted area. Plants grafted onto both Rangpur lime and Swingle citrumelo rootstocks had transpiration affected by wetted area reduction. Even with higher root hydraulic conductivity, Rangpur lime root system was not able to meet water demand by plants in a different way under conditions of small soil volume explored by plant roots when wetting is partial.

Based on these results, the effect of the reduced wetted area in the soil was studied separately at each development stage, taking into account the evaporative demand class. The reduction in transpiratory rate was verified by Moreshet et al. (1983), who tested the irrigation of $40 \%$ of the area occupied by the plant, in a 23-year-old 'Shamouti' orange orchard. Moreshet et al. (1983) observed in this experiment, the mean soil water extraction in the plots with partially irrigated areas was $66 \%$ of the one in fully irrigated plots, the transpiration in one of the years (1980) was $72 \%$ and the evaporation from soil surface was $58 \%$. Based on these data, Cohen et al. (1984) concluded that there was an increment in water extraction of $40 \%$, but it was not enough to completely compensate the reduction in the water available in the $60 \%$ dry zone.

Analyzing all the period, the number of days after applying partial irrigation in the soil plays an important role in the reduction of plant transpiration when subjected to restriction in a wetted area. PTr increased on average $1 \%$ per five days, a highly expressive relationship ( $p$ $<0.001$ ), suggesting an acclimation of the root system to the wetted soil volume at around 156 days. However, the relationship between PTr and the number of days after irrigation is not uniform throughout the period. Low PTr values around 90 days can be seen, after the beginning of partial irrigation, when the vegetative growth period is over (Figure 2).

The ratio $\mathrm{Tr} /$ ETo ranged from 0.4 to $4.2 \mathrm{~L} \mathrm{~mm}^{-1}$ $\mathrm{d}^{-1}$. Tr/ETo is predominantly growing until the end of May (79 days after partial irrigation); this behavior can be explained by the increase in plant leaf area and, consequently, in transpiration. In the development stage, until plants reach their maximum growth, the formation of new leaves is greater than the falling of old leaves. In this period, plants with $12 \%$ WA showed a sharp increase in Tr/ETo and, throughout time, values reached similar levels to those of $100 \%$ WA plants.

Flowering was induced by low temperatures, not being necessary induction by water deficit. According to Davenport (1990), for floral induction to happen, temperatures of, at most, $22{ }^{\circ} \mathrm{C}$ are necessary. In the threeweek period before the beginning of the flowering stage had been verified, average temperatures varied from 16.6 to $22.7{ }^{\circ} \mathrm{C}$, minimum temperatures from 8.9 to 17.7 ${ }^{\circ} \mathrm{C}$ and maximum temperatures from 21.4 to $34.1{ }^{\circ} \mathrm{C}$. Nearly 40 days before flower buds were observed, $\mathrm{Tr} /$ ETo values showed a descending trend. Falling of old

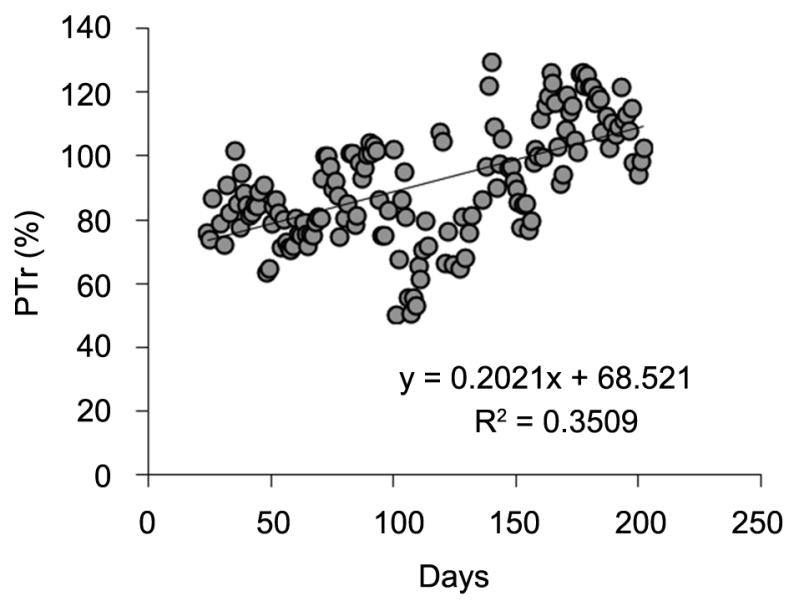

Figure 2 - Percentage of transpiration relative to $100 \%$ of soil wetted area (PTr) as a function of the number of days after partial irrigation beginning. 
leaves was observed in the field, possibly because of the translocation of nutrients to the flowering and because of the low temperature stress effect, which can explain the reduction in $\mathrm{Tr} / \mathrm{ETo}$. In plants with a reduction in wetted area, this behavior was more pronounced and the transpiration, which was similar to that in $100 \%$ WA plants at the end of the vegetative period, showed a reduction. After the observation of flower buds, and in the period of fruit formation and filling, Tr/ETo values did not show differences between plants with and without wetted area restriction.

The percentage of transpiration relative to $100 \%$ of soil wetted area (PTr) reveals that at the beginning of the experiment all the area in the box was irrigated and plants transpired around $100 \%$, with low variability, which is natural to this type of experiment. When irrigation was changed to only $12 \%$ of the box area, there was a reduction in transpiration in all the plants, which was linear with time, until the other compartments were dry, which occurred around 14 days. After this period, transpiration oscillated from 42 to $130 \%$ of the transpiration relative to $100 \%$ of soil wetted area. Such oscillation was due mainly to the plants' phenological stage, atmospheric evaporative demand and the acclimation of the root system to the wetted soil (Figure 3).

As reported by Vellame et al. (2012), in the same experiment with $100 \%$ WA plants, it was observed that for low ETo values there is a linear trend of increase in plant transpiration with the increase in the atmospheric evaporative demand. For ETo values above a certain value, there is a trend of stabilization in transpiration. The value of $2.0 \mathrm{~mm} \mathrm{~d}^{-1}$ as a limit between high and low demand classes was chosen because of the smaller error (RMSE) in the general estimation of transpiration (Figure 4). This limit, lower than the one found for plants with no wetted area restriction $\left(2.4 \mathrm{~mm} \mathrm{~d}^{-1}\right)$, indicates a greater control in water loss by plants under a condition of partial soil wetting, with possible implications for the photosynthetic rate.

Citrus plants have the capacity to maintain water in their tissues due to the high resistance to water vapor diffusion of their stomata and the waxiness of their leaves. When the water demand increases in the atmosphere, the transpiration rate is reduced because of an increase in stomatal resistance. The high leaf resistance to water vapor diffusion in citrus becomes a limiting factor for transpiration, giving plants similar maximal values in highly contrasting regions in terms of atmospheric demand. Besides the characteristics of high resistance to water vapor diffusion, citrus have some sort of adaptive response, when exposed to high atmospheric demand for a certain period (Hall et al., 1975; Syvertsen and Lloyd, 1994). Girardi et al. (2010) observed in citrus trees that there was temporary reduction in sap flow in periods of maximum water stress, usually observed at noon, which can be attributed possibly to stomatal closure.

There was a decrease in the difference between transpiration of plants with and without restriction of wetted area over time (Table 2). In the vegetative growth period, the difference between treatments in high atmospheric evaporative demand days was on average 25 $\%$, while by the end of the evaluations that difference dropped to $6 \%$ in the same demand class. The average differences in transpiration were not only lower over time, but also had lower probabilities of being different. These results suggest an acclimation of the root system to the reduced volume of wetted soil. This acclimation was also observed by Zekri and Parsons (1989), with tree roots confined to a small soil volume in arid climates, adapting well to a small volume wetted by micro-sprinklers. Pires et al. (2011) concluded that the treatment with only one drip line per planting row had the highest
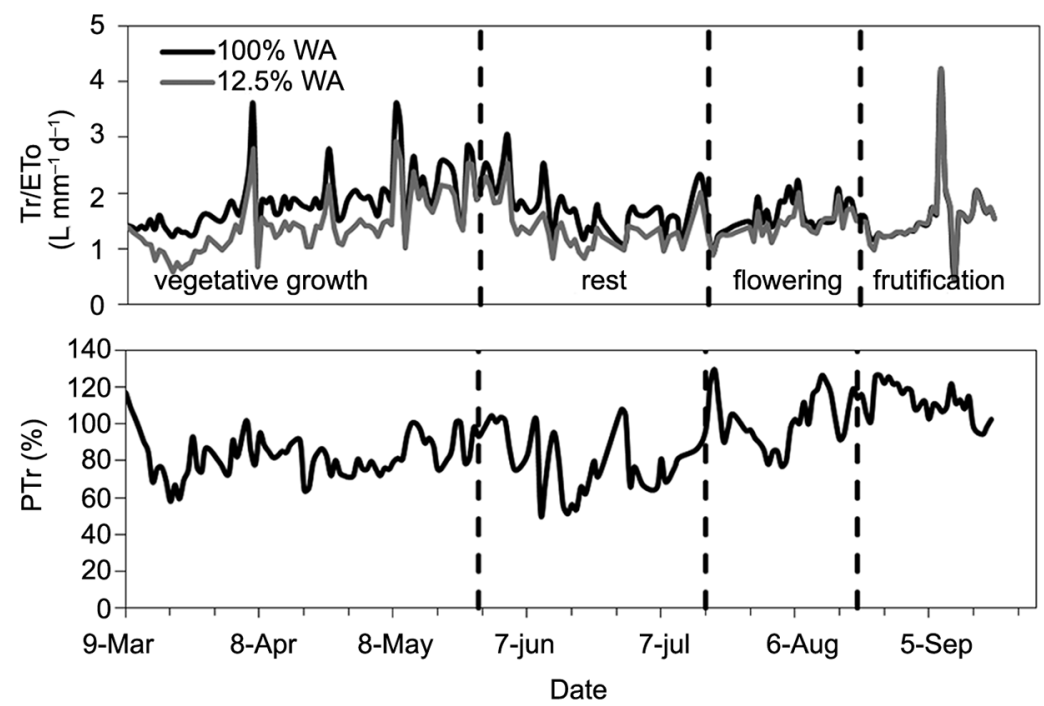

Figure 3 - Relationship between mean daily transpiration and reference evapotranspiration (Tr/ETo) and percentage of transpiration relative to $100 \%$ of soil wetted area (PTr). 

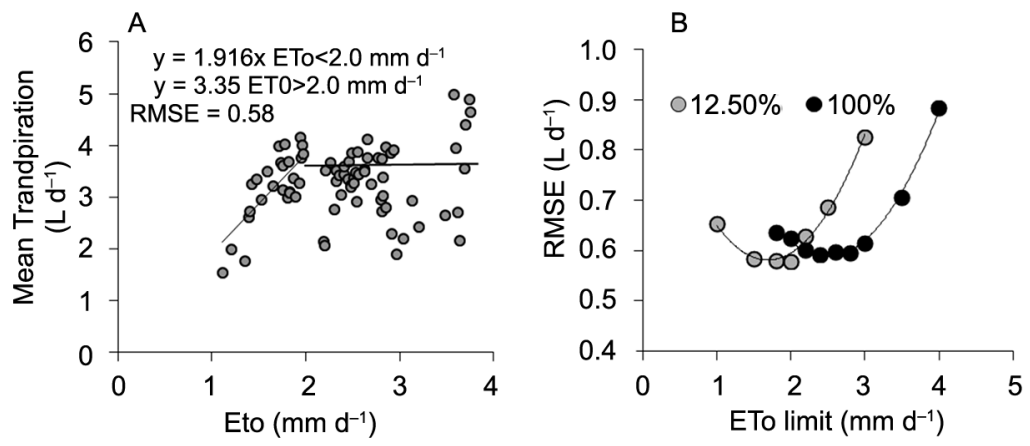

Figure 4 - Relationship between mean daily transpiration of plants with $12 \%$ of soil wetted area and the reference evapotranspiration (ETo) (A). Root mean square error (RMSE) as a function of ETo values divided into high and low demand classes (ETo limit) (B).

Table 2 - Daily mean transpiration in days of high and low reference evapotranspiration (ETo) with $100 \%$ and $12 \%$ of soil wetted area (WA) and probability of difference ( $p)$.

\begin{tabular}{|c|c|c|c|c|c|}
\hline \multirow{2}{*}{$\begin{array}{l}\text { Phenological } \\
\text { Stage }\end{array}$} & \multirow{2}{*}{ ETo } & \multicolumn{2}{|c|}{ Mean Transpiration $\left(\mathrm{L} \mathrm{d}^{-1}\right)$} & \multirow{2}{*}{ Difference } & \multirow{2}{*}{$p$} \\
\hline & & $100 \%$ WA & $12 \%$ WA & & \\
\hline & $\mathrm{mm} \mathrm{d}^{-1}$ & & & $\%$ & \\
\hline Vegetative & $>2.0$ & 4.65 & 3.48 & 25.2 & $<0.001$ \\
\hline growth & $<2.0$ & 3.59 & 3.22 & 10.2 & 0.155 \\
\hline Rest & $<2.0$ & 2.87 & 2.40 & 16.4 & 0.070 \\
\hline Flowering & $<2.0$ & 3.33 & 3.12 & 6.40 & 0.409 \\
\hline Frutification & $>2.0$ & 3.99 & 3.76 & 5.71 & 0.378 \\
\hline
\end{tabular}

root concentration in the wet bulb, compared with treatments with two and four drip lines. The results for root length density found in this study reinforce the hypothesis of the root acclimation effect.

In the period preceding the observation of flower buds (rest), means are different at $7 \%$ of significance while in the vegetative growth period for the same ETo class (low) this value is $15 \%$. It happens because of the increase in the difference between transpirations in the periods (16\% and $10 \%)$, indicating that plant metabolic activities related to the flowering influence transpiration, demanding a larger wetted soil volume. Besides the acclimation of root system and phenological stage of plants, ETo influences the reduction in transpiratory rate when the wetted area of the soil is reduced, which can be seen through the percentage differences in transpiration and their significances, during the vegetative growth period. At higher ETo values, roots in a reduced wetted volume of soil were not able to meet plant demand for water, while at lower values the differences between means were not significant.

\section{Root length density}

On average, the reduction of soil wetted area caused an increase of $78 \%$ in root length density when compared to $100 \%$ WA plants (Table 3). Regarding the non-irrigated compartments, the difference was $235 \%$. Therefore, in general, partial irrigation led to an increase
Table 3 - Mean root length density with $100 \%$ and $12 \%$ of soil wetted area (WA) for two types of soil.

\begin{tabular}{lcccc}
\hline \multirow{2}{*}{$\begin{array}{l}\text { Source of } \\
\text { variation }\end{array}$} & Type & \multicolumn{3}{c}{ Root length density $\left(\mathrm{cm} \mathrm{cm}^{-3}\right)$} \\
\cline { 3 - 5 } & & $12 \% \mathrm{WA}$ & $\begin{array}{c}\text { Non-irrigated } \\
\text { compartments }\end{array}$ & $100 \% \mathrm{WA}$ \\
\hline \multirow{2}{*}{ Soil } & Clay & $2.565 \mathrm{Aa}$ & $0.666 \mathrm{Ba}$ & $2.362 \mathrm{Aa}$ \\
& Sandy & $3.525 \mathrm{Ab}$ & $1.155 \mathrm{Ba}$ & $1.146 \mathrm{Bb}$ \\
\hline \multirow{2}{*}{ Rootstock } & 'Cravo' Lemon & $3.618 \mathrm{Aa}$ & $0.887 \mathrm{Ba}$ & $1.540 \mathrm{Ba}$ \\
& $\begin{array}{c}\text { 'Swingle' } \\
\text { Citrumelo }\end{array}$ & $2.472 \mathrm{Ab}$ & $0.934 \mathrm{Ba}$ & $2.057 \mathrm{ABa}$ \\
\hline Mean & & $3.045 \mathrm{~A}$ & $0.910 \mathrm{~B}$ & $1.786 \mathrm{C}$ \\
\hline
\end{tabular}

Means followed by the same letter, upper case in rows and lower case in columns, in the same source of variation, do not differ by Tukey test at $5 \%$ of probability.

in root concentration in the irrigated compartment, which explains the increase in relative transpiration in the $12 \%$ WA treatments over time. In the irrigated compartment of boxes with reduction in wetted area, there was a higher concentration of roots in the sandy soil. The rootstock Rangpur lime showed greater root growth than the 'Swingle' citrumelo under these conditions. Similar results were found by Pires et al. (2011) who observed that $80 \%$ of the roots were found in the wet bulb, from 0.20 to $0.25 \mathrm{~m}$; and by Coelho et al. (2002), in three different citrus rootstocks.

\section{Root-soil water extraction}

A source of error in the experiment is the uneven distribution of the root system in the box compartments. Table 4 shows the results of the percentage of water extraction in each compartment in relation to total consumption before administering the reduced wetted area treatment. Good uniformity can be seen with values within the expected range, given the inherent variability in this type of experiment.

After 225 days of administering the wetted area fraction treatment $(12 \%)$, the total volume of soil was irrigated and taken to field capacity. In the first $48 \mathrm{~h}, 50$ and $80 \%$ of water extraction in the clay and sandy soil, respectively, came from the position to which the root system was adapted, i.e., $12 \%$ of the total volume (Figure 5). This relationship dropped drastically in the sandy 
Table 4 - Mean, coefficient of variation (CV) and confidence interval (I) of the fraction of total water extraction in each box compartment in a 16-day period, before wetted area reduction.

\begin{tabular}{lccc}
\hline & \multicolumn{3}{c}{ Compartments } \\
\cline { 2 - 4 } & 12 & 25 & 50 \\
\cline { 2 - 4 } Mean & 0.125 & 0.247 & 0.510 \\
CV & $25 \%$ & $16 \%$ & $10 \%$ \\
I (95\%) & 0.009 & 0.016 & 0.022 \\
\hline
\end{tabular}

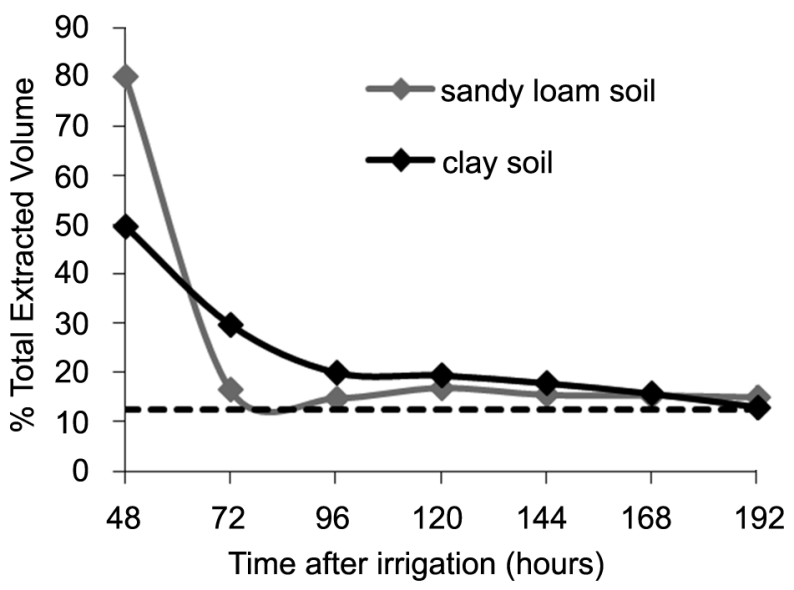

Figure 5 - Mean percentage of water extraction by plants in the irrigated compartment (12\%) after partial irrigation period.

soil (17\%), after $72 \mathrm{~h}$ of irrigation, and less markedly in the clay soil (30\%). After $96 \mathrm{~h}$, there was stabilization of water extraction in the sandy soil $(15 \%)$ and a minor representation in the clay soil $(20 \%)$. After $192 \mathrm{~h}$, there was stabilization of water extraction in the compartment of 12 $\%$ of the total soil volume, being $15 \%$ for sandy and $13 \%$ for clay soil, which is very close to their proportionality in volume, even after a long period of acclimation.

Results showed fast resumption of root activities (7 days) even after a long period without irrigation, in spite of the decrease in growth, observed in root length density data. The water redistribution in the root system was evident, maintaining the integrity of the roots in dry soil area. In this study, it was not possible to evaluate whether the fast establishment of water extraction was caused by the absorption through either old roots or new thin roots that appeared during the short period. In addition, the extraction capacity is not strongly correlated with root concentration, which may be explained by the adaptation of many perennial plants to water extraction at great depths. Studies have shown that water extraction by roots is not always linear with root length density (Clothier and Green, 1994).

\section{Vegetative growth}

Besides the significant reduction in transpiratory rate in the months preceding flowering, there was no difference $(p>0.05)$ between treatments with 12 and $100 \%$ of soil wetted area, in terms of vegetative growth, as can be observed through the analysis of variance for stem diameter and leaf area.

Plant growth and yield depend on the photosynthesized substrate supply, when favored by conditions suitable to high photosynthesis rates. In general, where water is deficient, the drop in photosynthesis is due to stomatal closure. Depending on the species, nature and intensity of the dehydration, photosynthetic rates can reach values close to zero without a significant decline in mesophyll photosynthetic capacity (Chaves, 1991). Machado et al. (2002). In 'Valencia' orange trees, observed through leaf water potential measurements variations in temperature, air humidity and solar radiation conditions influenced leaf water status, but the magnitudes were apparently not enough to affect photosynthetic rates. Bielorai (1982) observed that water use efficiency was greater in the drip-irrigated plots than in the sprinkled ones, and also greater in the plots given the under reduced water applications $180 \%$ of the maximum seasonal amount of the irrigation water applied), as compared with plots receiving the full amount of irrigation.

This study shows the potential of irrigation in a small wetted area (single line of drippers) and management strategies like PRD. The results demonstrate the high adaptive capacity of the plants studied regarding partial soil wetting, with strong acclimation of their root system to the wetted volume. Even with differences in transpiration in some periods, the reduction of the wetted area did not provoke differences in plant growth. The fast recovery of the absorption capacity by the portion of the roots without wetting demonstrates that, despite root acclimation to the wetted area, these plants can be efficient at using rainwater.

Field conditions, in general, are less restrictive regarding soil water distribution than the controlled conditions in this study. However, in field conditions, with higher atmospheric water demand, even with higher root concentrations in the wetted area, it is possible that roots are not capable of absorbing water as in total wetting conditions. Thus, field experiments monitoring transpiration and soil wetted volume under higher ETo variations are necessary to validate the results.

\section{Conclusions}

There is a reduction in transpiration of 'Valência' orange trees due to the restriction in soil wetted area, and such reduction is influenced by the number of days after the beginning of partial irrigation, atmospheric evaporative demand and plant phenological stage. Plant transpiration around 156 days after the beginning of partial irrigation was equivalent to that of plants with 100 $\%$ of wetted area, and this acclimation is caused by an increase in root concentration in the irrigated area. After an acclimation period, where the entire root system 
is wetted, soil water extraction becomes proportional to the percentage of wetted area after a short period of time. Despite the reduction in transpiratory rate, there was no difference between treatments with 12 or 100 $\%$ of soil wetted area regarding the vegetative growth.

\section{References}

Allen, R.G.; Pereira, L.S.; Raes, D.; Smith, M. 1998. Crop Evapotranspiration. Guidelines for Computing Crop Water Requirements. FAO, Rome, Italy. (Irrigation and Drainage Paper, 56).

Bielorai, H. 1982. The effect of partial wetting on the root zone on yield and water use efficiency in a drip and sprinkler-irrigated mature grapefruit grove. Irrigation Science 2: 89-100.

Castel, J.R. 1994. Response of young Clementine citrus trees to drip irrigation. I. Irrigation amount and number of drippers. Journal of Horticultural Science \& Biotechnology 69: 481-489.

Chaves, M.M. 1991. Effects of water deficits on carbon assimilation. Journal of Experimental Botany 42: 1-16.

Clothier, B.E.; Green, S.R. 1994. Root zone processes and the efficient use of irrigation water. Agricultural Water Management 25: 1-12.

Coelho, R.D.; Vellame, L.M.; Fraga Júnior, E.F. 2012. Estimation of transpiration of the 'Valencia' orange young plant using thermal dissipation probe method. Engenharia Agrícola 32: 573-581.

Coelho, E.F.; Oliveira, F.C.; Araújo, E.C.E.; Vasconcelos, L.F.L. 2002. Root distribution of "Pêra" orange trees under nonirrigated and irrigated conditions in a sandy soil. Pesquisa Agropecuária Brasileira 37: 603-611 (in Portuguese, with abstract in English).

Coelho Filho, M.A.; Angelocci, L.R.; Campeche, L.F.S.M.; Folegatti, M.V.; Bernardes, M.S.B. 2005. Field determination of young acid lime plants transpiration by the stem heat balance method. Scientia Agricola 62: 240-247.

Cohen, Y.; Moreshet, S.; Fuchs, M. 1984. Change in transpiration rate of mature citrus trees in response to a reduction of wetted soil volume. Acta Horticultural 171: 45-50.

Davenport, T.L. 1990. Citrus flowering. Horticultural Review 12: 349-408.

Domingo, R.; Ruiz-Sánchez, M.C.; Sánchez-Blanco, M.J.; Torrecillas, A. 1996. Water relations, growth and yield of Fino lemon trees under regulated deficit irrigation. Irrigation Science 16: 115-123.

Ferreira, M.I.; Silvestre, J.; Conceição, N.; Malheiro, A.C. 2012. Crop and stress coefficients in rainfed and deficit irrigation vineyards using sap flow techniques. Irrigation Science 30: 433-447.

Genuchten, M.Th. van. 1980. A closed-form equation for predicting the hydraulic conductivity of unsaturated soils. Soil Science Society of America Journal 44: 892-898.
Girardi, E.A.; Mourão Filho, F.A.A.; Delgado-Rojas, J.S.; Araújo, J.P.C. 2010. Use of the heat dissipation method for sap flow measurement in citrus nursery trees. Revista Brasileira Fruticultura 32: 976-983.

Hall, A.E.; Camacho, B.S.E.; Kauffman, M.R. 1975. Regulation of water loss by citrus leaves. Physiologia Plantarum 33: 62-65.

Hutton, R.J.; Loveys, B.R. 2011. A partial root zone drying irrigation strategy for citrus: effects on water use efficiency and fruit characteristics. Agricultural Water Management 98: 1485-1496.

Koo, R.C.J. 1985. Response of 'Marsh' grape fruit trees to drip, under tree spray and sprinkler irrigation. Proceedings of the Florida State Horticultural Society 98: 29-32.

Lu, P.; Woo, K.C.; Liu, Z.T. 2002. Estimation of whole-plant transpiration of bananas using sap flow measurements. Journal of Experimental Botany 53: 1771-1779.

Machado, E.C.; Medina, C.L.; Gomes, M.M.A.; Habermann, G. 2002. Seasonal variation of photosynthetic rates, stomatal conductance and leaf water potential in 'Valencia' orange trees. Scientia Agricola 59: 53-58 (in Portuguese, with abstract in English).

Moreshet, S.; Cohen,Y.; Fuchs, M. 1983. Response of mature 'Shamouti' orange trees to irrigation of different soil volumes at similar levels of available water. Irrigation Science 3: 223-236.

Pires, R.C.D.M.; Bodine Junior, D.; Sakai, E.; Villar, H.L.; da Silva, T.J.; Arruda, F.B. 2011. Effect of trickle irrigation on root development of the wet bulb and 'pera' orange tree yield in the state of São Paulo, Brazil. Engenharia Agrícola 31: 1096-1103.

Steppea, K.; Pauwb, D.J.W.; Doodyc, T.M.; Teskey, R.O. 2010. A comparison of sap flux density using thermal dissipation, heat pulse velocity and heat field deformation methods. Agricultural and Forest Meteorology 150: 1046-1056.

Syvertsen, J.P.; Lloyd, J.J. 1994. Cítrus. p. 65-99. In: Schaffer, B.; Andersen, P.C., eds. Handbook of environmental physiology of fruits crops: subtropical and tropical crops. CRC Press, Boca Raton, FL, USA.

Treeby, M.T.; Henriod, R.E.; Bevington, K.B.; Milne, D.J.; Storey, R. 2007. Irrigation management and rootstock effects on navel orange [Citrus sinensis (L.) Osbeck] fruit quality. Agricultural Water Management 91: 24-32.

Vellame, L.M.; Tolentino, J.B.; Coelho, R.D. 2012. Transpiration of young plants of Valencia orange in rootstock Rangpur and Swingle in two types of soil. Revista Brasileira de Fruticultura 34: 24-32 (in Portuguese, with abstract in English).

Yonemoto, Y.; Matsumoto, K.; Furukawa, T.; Asakawa, M.; Okuda, H.; Takahara, T. 2004. Effects of rootstock and crop load on sap flow rate in branches of 'Shirakawa Satsuma' mandarin (Citrus unshiu Marc.). Scientia Horticulturae 102: 295-300.

Zekri, M.; Parsons, L.R. 1989. Grapefruit leaf and fruit growth in response to drip, micro sprinkler, and overhead sprinkler irrigation. Journal of the American Society for Horticultural Science 114: 25-29. 